\title{
EDAPHIC MESOFAUNA COMMUNITY STRUCTURE IN ORGANIC AND CONVENTIONAL MANAGEMENT OF CRANBERRY (Vaccinium sp.) PLANTATIONS: AN AGROECOLOGICAL APPROACH
}

\author{
Santiago F. Peredo P. ${ }^{1,2^{*}}$, Esperanza Parada Z., ${ }^{3,1}$, Marcela Vega C. ${ }^{3}$, \\ Claudia P. Barrera S. ${ }^{1}$ \\ ${ }^{1}$ Grupo de Investigación en Gestión de la Calidad Agroalimentaria, ${ }^{2}$ Depto. Gestión Agraria, \\ Facultad Tecnológica, Universidad de Santiago de Chile. Ecuador 3769, Estación Central, \\ Santiago, Chile. Phone: 56-2-7180585; ${ }^{3}$ Escuela de Ciencias Ambientales, Facultad de Recursos \\ Naturales, Universidad Católica de Temuco. Temuco, Chile. \\ *Corresponding author: santiago.peredo@usach.cl
}

\begin{abstract}
The aim of the present study was to determine and compare taxa richness, abundance and diversity of the edaphic mesofauna community between plantations of cranberries (Vaccinium sp.) subjected to organic and conventional management in farms in central-south Chile $\left(37^{\circ} 28^{\prime} \mathrm{S}\right)$, as also to evaluate changes produced in their diversity and abundance diversity and abundance, as result of the change from conventional to organic management. In July 2006 two farms were chosen, one with one year under organic management (OM1) and a second one under six years of certified organic management (OM6). Each farm was divided in four quadrants, each one with a surface of $2,500 \mathrm{~m}^{2}$. In each quadrant was extracted one sample with six replicas of $188.5 \mathrm{~cm}^{3}$ each. Samples were processed in the laboratory using the Berlesse-Tullgren system for the extraction of mesofauna and the subsequent counting and identification of specimens. To compare the organic managed plantation, it was selected a farm under conventional management (CM) with similar climatic and edaphic conditions. On each parcel, taxa richness, abundance, alpha $(\alpha)$ diversity, dominance and beta $(\beta)$ diversity were determined. Significant differences between diversity values were determined with Student's t test $(\alpha=0.05)$. It is concluded that taxa richness is similar in all plantations, independent of agricultural management, whereas abundance of each taxon individually is different between both types of management. There are significant differences in diversity between the organic plantations (OM1 versus OM6) and between the conventional $(\mathrm{CM})$ versus organic plantations $(\mathrm{P}<0.05)$. Qualitative (taxocenotic) and quantitative (biocenotic) similarity recorded in the edaphic communities from both types of plantation management may be explained by soil type and climate similarity, as well as by the homogeneity of the edaphic ecosystem.
\end{abstract}

Keywords: edaphic mesofauna, organic farming, conventional farming, Vaccinium sp., mediterranean climate.

\section{INTRODUCTION}

At the level of arable and livestock farming, emphasis has been placed on the importance of edaphic fauna for sustainable agriculture, based on their multiple functions in the ecosystem
(Primavesi, 1990, Hendrix et al. 1990, Crossley et al. 1992, Stork and Eggleton, 1992, André et al. 2001). In fact, it has been shown that the management practices carried out in organic agriculture 
increase the functional diversity of edaphic micro-arthropods (Paoletti and Pimentel, 1992, Mader et al. 2002, Benttsson et al., 2005, Diepeningen et al., 2006) as compared with conventionally practices (Lara et al. 1986, Doles et al. 2001, Peredo et al. 2002).

In Chile, there are no studies on community structure of edaphic mesofauna in soils subjected to organic management. In this respect, we have hypothesized that when organic management is started in a plantation after a conventional management, the incorporation of high amounts of organic material to the soil will increase the diversity of resources for edaphic organisms. Therefore, we may expect to find a community structure conformed by a great diversity of taxa at low abundance in cranberries (Vaccinium sp.) plantations in a transitional year from conventional to organic management. On the other hand, in plantations subjected for a longer period to organic management, we can expect to find only those mesoedaphic organisms which adapt to this condition, with a reduction in the diversity of taxa, but an increase in the abundance of the species. At the same time, we expect that the edaphic community structure of plantations under conventional agricultural practices will be different on diversity and abundance compared to organic practices. In this context, the objectives of this research were i) to determine and compare taxa richness, abundance and diversity of the edaphic mesofauna community structure between cranberries plantations subjected to organic and conventional management in farms of central-south Chile, and ii) to evaluate the changes in their diversity and abundance, as a result of management change, from a conventional to an organic one.

\section{MATERIALS AND METHODS}

\section{Study area}

The study was carried out in a private farm in cranberries plantations located 15 $\mathrm{km}$ west of the city of Los Angeles, BíoBío Region, Chile ( $\left.37^{\circ} 28^{\prime} \mathrm{S}\right)$. The climate of the zone is Mediterranean. The mean annual precipitation is $1,303 \mathrm{~mm}$, mostly concentrated between March and August. The maximum average temperature of the warm period (January) is $29^{\circ} \mathrm{C}$ and the minimum average temperature of the cold period (July) is $5^{\circ} \mathrm{C}$ (Del Pozo and Del Canto, 1999). The soils are derived from volcanic ashes deposited recently over an unrelated substrate, which is compacted but not cemented, with slow permeability. The soils are very deep, well drained, with high humidity retention (Tosso, 1985).

Organic management utilizes inputs allowed by international certification norms, consisting mainly in the periodic incorporation of compost elaborated with manure obtained from intensive poultry farms, complemented with the incorporation of phosphoric rock in winter and compost tea through the irrigating system. Weed control is carried out by mechanic methods, complemented with the establishment of between-row winter crops, which in addition allow curculionid larvae control.

On the other hand, in the conventional management, soil is fertilized with phosphorous (triple superphosphate) in fall and nitrogen (urea) in spring, by means of synthetic chemical products. Weed control is done mechanically complemented with herbicides (Gliphosate and Azolan) and preemergent residual herbicides (Simazine plus Pendimethanyl) in spring. 


\section{Sampling design}

In July 2006, two farms were chosen, one with one year under organic management (OM1) and a second one under six years of certified organic management (OM6). The OM1 was considered as a transition plantation, since it had previously been conventionally managed. Each farm was divided in four $2,500 \mathrm{~m}^{2}$ quadrants. In each quadrant was extracted one sample with six replicates of $188.5 \mathrm{~cm}^{3}$ each. The extraction was done with a corer to a depth of $15 \mathrm{~cm}$. This depth was established in consideration of the depth levels with the greatest presence and activity of edaphic mesofauna (Neher and Barbercheck, 1999). The samples were mounted over seven days using a modified Berlesse-Tullgren system (Lara et al., 1986) to ensure the extraction of the edaphic organisms. The organisms were collected in alcohol at $75 \%$ and the specimens obtained were studied under a stereoscopic microscope, counted and identified taxonomically at the level of order and sub-order, to compare and analyse diversity and abundance of the edaphic mesofauna. To compare the organic managed plantation, it was selected a farm under conventional management $(\mathrm{CM})$ with similar climatic and edaphic conditions.

\section{Data analysis}

The richness and abundance of taxa per plot were estimated, as also the diversity and homogeneity of the mesofauna groups in each plantation (CM, OM1 and OM6) (sensu Doles et al., 2001). The density was estimated in $\left(\mathrm{n} \mathrm{m}^{-2}\right)$. The $\alpha$ diversity and dominance were calculated using the Shannon (H') Index (Cox, 1968) and the Homogeneity (Equity) Index (J) (Krebs, 1985). In addition, the $\beta$ diversity was determined to establish the taxocenotic and biocenotic similarities using the Bray Curtis Index estimated with the Biodiversity Pro software. To evaluate whether significant differences exist between the values of the diversity indices obtained in the two communities in the first year, Student's t test $(\alpha=0.05)$ was applied (Zar, 1999)

\section{RESULTS AND DISCUSSION}

Table 1 shows the taxa recorded in the present study, with their respective abundances and densities. In both the organically managed and the conventional plantations, the same taxa of edaphic mesofauna were recorded, with the exception of Protura, recorded only in the plantation with conventional management (CM), and Diplopoda only in the organic management plantation, in both cases with very low abundance (Table 1).

The most abundant taxa were Acarina and Collembola. Differences in abundance appeared between the organic plantations (OM1 and OM6) and the conventionally managed plantation (CM). In this sense, although the presence/absence of edaphic mesofauna groups was similar in the two cranberries plantations (organic and conventional management), clear differences were observed in the abundance of each taxon in the different plantations.

The most abundant taxon of edaphic mesofauna in all the cranberries plantations under organic management was Acaridida, followed in descending order by Oribatida, Tarsonemida and Gamasida; Entomobryomorpha was the most abundant of the Collembola (Table 1). In the plantation under conventional management (CM), the most abundant taxa of mites were Oribatida and Prostigmata, and Poduromorpha among the Collembola. Regarding the analysis of values between the organic plantations, in OM1 were recorded 235 individuals of Oribatida (24 samples). 
Table 1. Abundance (A), mean (X), standard deviation (DE) and density (D) of edaphic mesofaunistic taxa present in conventional management Vaccinium sp. plantation (CM) versus Vaccinium sp. plantations with one(OM1) and six (OM6) years of organic management in Central-South Chile.

\begin{tabular}{|c|c|c|c|c|c|c|c|c|c|}
\hline \multirow[b]{2}{*}{ Taxa } & \multicolumn{3}{|c|}{$\mathbf{C M}$} & \multicolumn{3}{|c|}{ OM1 } & \multicolumn{3}{|c|}{ OM6 } \\
\hline & A & $\mathrm{X}(\mathrm{DE})$ & D: $\mathbf{n} / \mathbf{m}^{2}$ & A & $\mathrm{X}(\mathrm{DE})$ & D:n/m $\mathbf{m}^{2}$ & A & $\mathrm{X}(\mathrm{DE})$ & D: $\mathbf{n} / \mathbf{m}^{2}$ \\
\hline Oribatida & 725 & $29(26)$ & 14500 & 235 & $9.4(6.6)$ & 4700 & 404 & $16.2(13)$ & 8100 \\
\hline Gamasida & 65 & $2.6(3.5)$ & 1300 & 108 & $4.3(3.1)$ & 2150 & 104 & $4.2(3.4)$ & 2100 \\
\hline Uropodina & 9 & $0.4(26)$ & 200 & 6 & $0.2(0.5)$ & 100 & 12 & $0.5(0.8)$ & 250 \\
\hline Prostigmata & 117 & $4.7(3.5)$ & 2350 & 34 & $1.4(1.2)$ & 700 & 33 & $1.3(1.5)$ & 650 \\
\hline Tarsonemida & 50 & $2(2.7)$ & 1000 & 179 & $7.2(8.2)$ & 3600 & 95 & $3.8(6)$ & 1900 \\
\hline Acaridida $(\mathrm{A}+\mathrm{L})$ & 52 & $1.4(4)$ & 700 & 255 & $10.1(19)$ & 5050 & 493 & 16.(60) & 8250 \\
\hline Total Acarina & 1018 & & & 817 & & & 1141 & & \\
\hline Entomobryomorpha & 38 & $1.5(2.3)$ & 750 & 114 & $4.6(6.6)$ & 2300 & 69 & $2.8(2.9)$ & 1400 \\
\hline Poduromorpha & 128 & $5.1(6.7)$ & 2550 & 83 & $3.3(5.7)$ & 1650 & 70 & $2.8(3.7)$ & 1400 \\
\hline Symphypleona & 0 & 0 & 0 & 0 & 0 & 0 & 0 & 0 & 0 \\
\hline Total Collembola & 166 & & & 197 & & & 139 & & \\
\hline Diplopoda & 0 & 0 & 0 & 4 & $0.2(0.5)$ & 350 & 2 & $0,1(0,3)$ & 50 \\
\hline Quilopoda & 8 & $0.3(0.9)$ & 150 & 3 & $0.1(0.3)$ & 50 & 1 & $0,04(0,7)$ & 20 \\
\hline Protura & 1 & $0.04(0.2)$ & 20 & 0 & 0 & 0 & 0 & 0 & 0 \\
\hline Diptera (L) & 1 & $0.04(0.2)$ & 20 & 20 & $0.8(2.6)$ & 400 & 3 & $0,1(0,3)$ & 50 \\
\hline Nematoda & 3 & $0.12(0.3)$ & 60 & 14 & $0.6(1.1)$ & 280 & 9 & $0,4(0,7)$ & 200 \\
\hline Total Abundance & 2378 & & 23540 & 2055 & & 21050 & 2566 & & 24170 \\
\hline Average values (X) & 158.5 & & 1810.8 & 137.0 & & 1619.2 & 171.1 & & 1859.2 \\
\hline
\end{tabular}


This value increased to almost double in OM6 (Table 1). According to BehanPelletier (2002), this group specialises in the exploitation of temporary habitats, behaving as a $+r$ strategist, with a high rate of reproduction and short life cycle ( 8 to $21 \mathrm{~d}$ ). This behavior is favoured by the hipopus, a larval stage which disperses effectively to habitats offering a high availability of food. Tarsonemida increased considerably in OM1, stabilising at lower abundances in plantations with longer periods of organic management. Next in abundance is Gamasida, with very similar abundances between the different plantations. Among Collembola, Entomobryomorpha and Poduromorpha are more abundant in OM1 than in OM6 (Figure 1).

In the plantation with conventional management (CM), Oribatida is the most abundant taxa, with higher values recorded than in plantations under organic management, reaching a total of 725 individuals in the 24 samples analysed, followed by Poduromorpha with 128 individuals and Prostigmata with 117 individuals per sample (Figure 1). Edaphic mesofaunistic studies carried out by Peredo et al. (2002) in plum plantations under conventional practices in the central region of Chile, reported only the presence of Gamasida and Uropodina (Acarina) in low abundance, as well as total absence of Collembolla. On the other hand, results of the present study on edaphic community structure in plantations under organic management fit with those obtained by Peredo et al. (2002) in naturalized prairies in the surroundings of plum plantations.

Table 2 shows the values for diversity $\left(H^{\prime}\right)$ and homogeneity $(\mathrm{J})$ for each type of plantation. Although the $\mathrm{H}^{\prime}$ values are similar between the organic plantations, the highest value was recorded in OM1. This fact was as expected, since this plantation is considered in transition to organic management, in which the agrochemical consumables of the pre-existing conventional management are being replaced by other low energy alternatives, allowing a greater inward movement of different edaphic groups in search of food, thus increasing biodiversity (Altieri, 1999). In the other organic plantation (OM6), given the longer period under this management, the stability in the diversity values of the edaphic mesofauna taxa would be explained by the accumulation of organic material, providing a substrate which releases nutrients and appropriate maintenance of the soil structure. This stability results in taxa richness, which would be represented by those groups which adapt best to organic management.

The differences in the $H^{\prime}$ values between OM1 and OM6, which show the highest and lowest values for $H^{\prime}$, respectively, were significant $(\mathrm{P}<0.05)$. Differences between the H' values of the conventional plantation and the $\mathrm{H}^{\prime}$ values of the organic ones were also significant $(\mathrm{P}<0.05)$, which would indicate changes in the edaphic mesofauna communities subjected to organic conversion. Studies done by Schrader et al. (2006) in communities of Collembola subjected to organic conversion in northern Germany (Trenthorst), also indicated an increase in diversity after three years. In the present study, the communities of microarthropods increased significantly their diversity values during the year of transition to organic management (OM1) and whereas in OM6 this parameter diminishes (to then get stabilized) at a value lower than in OM1, but higher than in $\mathrm{CM}$.

The homogeneity values (J') (Table 2) differed between $\mathrm{CM}$ and OM1. The lower value obtained in CM is explained by the high dominance of Oribatida, while the higher value obtained in OM1 is explained by their reduced dominance among the taxa. These results corroborate 


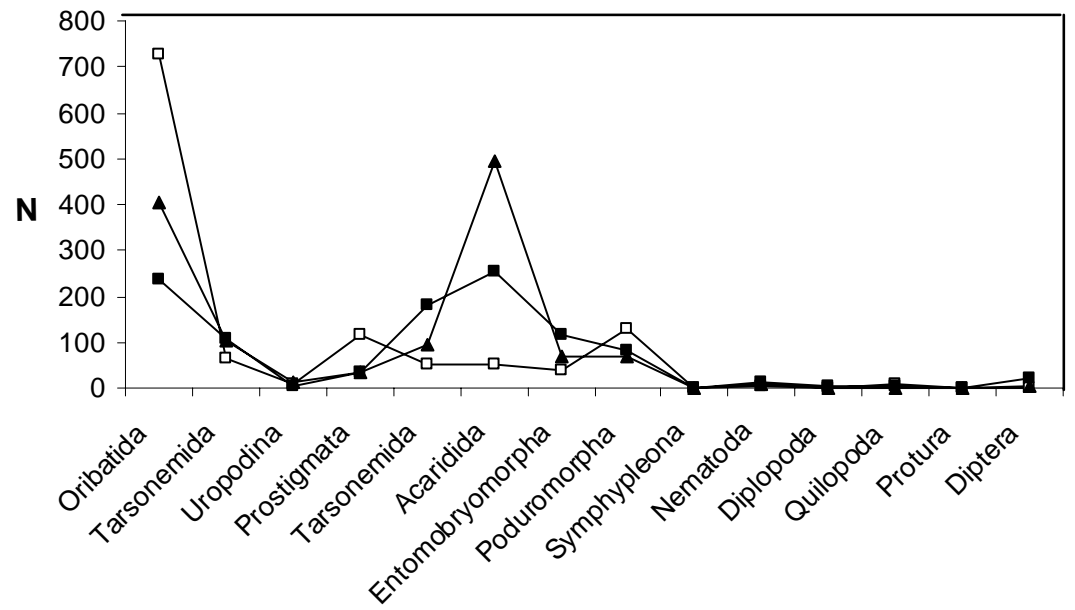

Figure 1. Comparison of abundance of edaphic mesofaunistic taxa present in conventional management Vaccinium sp. plantation $(\mathrm{CM})$ versus Vaccinium sp. plantations with one (OM1) and six (OM6) years of organic management in central-south Chile. (white square: $\mathrm{CM}$; black square: OM1; triangle: OM6).

Table 2. Diversity values (H'), highest diversity (H max), homogeneity (J) and edaphic mesofauna richness present in conventional management Vaccinium sp. plantation (CM) versus Vaccinium sp. plantations with one (OM1) and six (OM6) years of organic management in central-south Chile.

\begin{tabular}{lccc}
\hline Indexes & CM & OM1 & OM6 \\
\hline Shannon H' Log Base 10, & 0.61 & 0.852 & 0.712 \\
Shannon Hmax Log Base 10, & 1.079 & 1.079 & 1.079 \\
Shannon J' & 0.565 & 0.79 & 0.66 \\
Taxa Richness & 12 & 12 & 12 \\
\hline
\end{tabular}

the structural change experienced by the edaphic communities in cranberries plantations submitted to a management change (conventional to organic management) as was OM1.

As indicated above, there is a high taxocenotic (qualitative) similarity between the groups of edaphic mesofauna recorded between the plantations subjected to organic management (OM1 and OM6) and the taxa recorded in CM (Figure 2a). However, there are quantitative differences in the biocenosis of the edaphic communities in the two types of plantations, as is shown in Figure 2b. The dendrogram shows two similarity groups separated at the level of the $50.62 \%$, which separates the CM community from the organic plantations. At the same time, organic plantations (OM1 and OM6) are similar at 75\%. The great similarity would be explained by the similar niche conditions generated after the transition year. Bargett (2002) indicates that of the great number of studies done to date, few show 


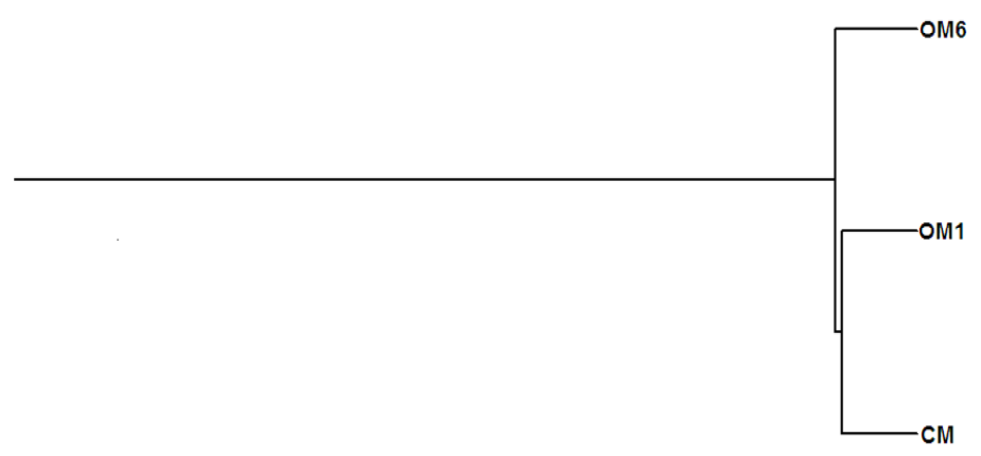

a

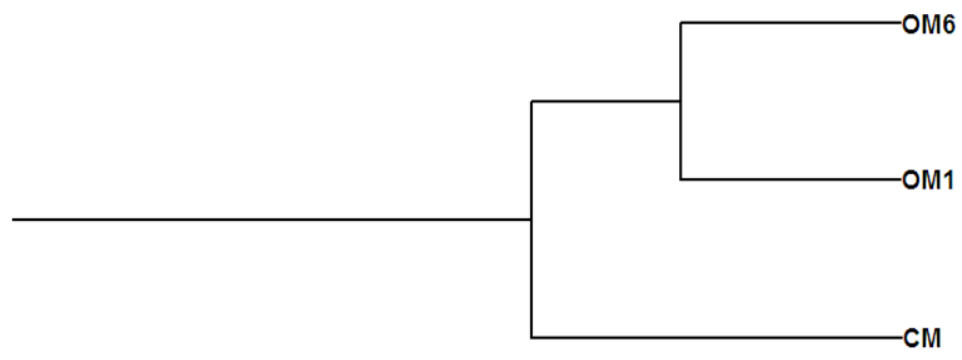

$0, \%$ Similarity

50

b

Figure 2. Taxocenotic (a) and biocenotic (c) similarity dendrogram of Vaccinium sp. plantation with conventional management $(\mathrm{CM})$ and Vaccinium sp. plantations with one (OM1) and six (OM6) years of organic management in central-south Chile in central-south Chile.

that edaphic diversity is regulated by competition or disturbances; rather, its regulation is attributable to the nature of the soil, given the extreme variety of habitats in both time and space provided by division by niche, resources or habitat specialization, thus allowing extensive coexistence of species or taxa. In this respect, the results of the present study indicated high qualitative and quantitative similarities between the communities of edaphic mesofauna in both types of management (organic and conventional).
This may be explained by similarities in the type of soil and climate, or those due to ecosystem homogeneity, since the weed control in this monoculture has an impact on the root homogeneity below the surface.

In this way, a similar habitat in both the $\mathrm{CM}$ and the OM plantations is provided, as well as a similar availability of resources for edaphic organisms, corroborating the indications of Bargett (2002). The results of the present study allow us to note that the Oribatidae 
is the dominant group of mites in the type of soil and climate where the cranberries plantations are located, although it is more satisfactorily expressed in plantations with conventional management. These results agree with Noti et al. (2003) who indicate that soil properties, especially moisture content, which increases in a greater proportion in the winter season in temperate climates, are fundamental for the expression of the abundance of Oribatidae. On the other hand, Acarididae is the taxa which presents the best expression in plantations with organic management and probably influences the development of the Oribatida, given the low abundance found in this type of plantation as compared with conventional management.

The high taxa richness (Table 2) in the organic plantations (OM1 and OM6) indicated that the ecosystem functions fulfilled by groups of edaphic mesofauna ensure stability and ecosystem services. Nevertheless, as in monocultures the biodiversity is reduced significantly, it would be useful to carry out proper management of the vegetation which accompanies the monoculture of cranberries. In this sense, the intensive management or cleaning carried out between the rows would make them to act as fragments of habitat at the scale of edaphic mesofauna, avoiding the exchange between species and the colonization of such spaces.

A greater environmental heterogeneity below the soil surface, provided by the diversity of plant roots, would ensure a greater edaphic biological diversity and the existence of all the functional groups, especially those taxa which have no equivalent trophic role. This would ensure that essential soil functions such as the nutrients cycling and carbon mineralization are expressed, increasing fertility and improving the soil structure. The importance of soil organisms for plants has been extensively proved in the last century and today there is no doubt that edaphic diversity is being considered as a tool for sustainable agriculture, hence the importance of making progress in knowledge of edaphic biodiversity in Chile.

\section{CONCLUSIONS}

Our results allow to conclude that taxa richness is similar in plantations with conventional (CM) and organic management (OM1 and OM6), whereas abundance of each taxon individually is different between both types of management. The highest value for diversity (H') and homogeneity (J) were observed in the plantation with one year of transition to organic management (OM1). At the same time, there are significant differences in diversity between both organic plantations, as well as between the conventional and the organic plantations. Qualitative and quantitative similarity recorded in the edaphic communities from both types of plantation management may be attributed to soil type and climate similarity, as also to the homogeneity of the edaphic ecosystem.

\section{ACKNOWLEDGEMENTS}

S.F. Peredo thanks Dr. Gloria Guzmán for her invitation to a research stay at the Ecological Agriculture and Rural Development Institute of Granada (CIFAED), which made possible the present article. This research was partially financed by the project "Fund for the Implementation of Research Units 2003" awarded to Esperanza Parada Z, for which the authors thank the General Directorate of Research and Postgraduate Studies of the Catholic University of Temuco. 


\section{REFERENCES}

Altieri, M.A. 1999. Dimensiones Multifuncionales de la Agricultura Ecológica en America Latina. Ed. PED-CLADES/CIED. Lima. 82pp.

André, H.M., Ducarme, X., Anderson, J.M., Crossley Jr, D.A., Koehler, H.H., Paoletti, M.G., Walter, D.E., Lebrun, P. 2001. Skilled eyes needed to go studying the richness of the soil. Nature 409: 761.

Bargett, R.D. 2002. Causes and consecuences of biological diversity in soil. Zoology 105, 367374.

Behan-Pelletier, V.M. 2002. Acari and collembolan biodiversity in Canadian agricultural soils. Can. J. Soil Sci. 83, 279-288.

Benttsson, J., Ahnström, J., Weibull, A.C. 2005. The effects of organic agriculture on biodiversity and abundance: a meta-analysis. J. App. Ecol. 42, 261-269.

Crossley, D.A., Mueller, B.R., Perdue J.C.1992. Biodiversity of microarthropods in agricultural soils: relations to processes. Agri. Ecosyst. Environ. 40, 37-46.

Cox, G.W. 1968. Laboratory Manual General Ecology. Brown Company Publishers. Iowa. 165 pp. 1968.

Del Pozo, A., Del Canto, P. 1999. Áreas agroclimáticas y sistemas productivos en la VII y VIII regiones. Instituto de Investigaciones Agropecuarias. Centro Regional de Investigación Quilamapu, Chile. 115 pp.

Diepeningen, A.D., Vos, O.J., Korthals, G.W. 2006. Effects of organic versus conventional management on chemical and biological parameters in agricultural soil. Appl. Soil. Ecol. $31,120-135$.

Doles, J.D., Zimmerman, R.J., Moore, J.C. 2001. Soil microarthropods community structure and dynamics in organic and conventionally managed apple orchards in Western Colorado, USA. Appl. Soil. Ecol. 18, 83-96.

Hendrix, P.F., Crossley Jr, D.A., Blair, J.M., Coleman, D.C. 1990. Soil biota as components of sustainable agroecosystems. In: Sustainable Agricultural Systems. Edwards, C.A., Lal, R., Madden, P., Miller, R.H., House, G. (Eds.). Soil and Water Conservation Society, USA. 637-654 pp.
Krebs, C.J. 1985. Ecología. Estudio de la distribución y abundancia. Ed. Harper \& Row Latinoamericana. México. 753 pp.

Lara, G., Parada, E., Butendieck, N. \& Covarrubias, R. 1986. Efecto de azinphos-etil sobre la densidad de microartrópodos del suelo en praderas de la IX Región (Chile). Ciencia e Investigación Agraria 13(2), 81-89.

Mader, P., Fliebach, A., Dubois, D., Gunst, L., Fried, P., Niggli, U. 2002. Soil fertility and biodiversity in organic farming. Science 296, 1694-1697.

Neher, D.A., Barbercheck, M.E. 1999. Diversity and function of soil mesofauna. In: Biodiversity in Agroecosystems. Collins, W.W., Qualset, C.O. CRC Press. USA. 27-47.

Noti, M.I., André, H.M., Ducarme, X. \& Lebrun, P. 2003. Diversity of soil oribatid mites (Acari: Oribatida) from High Katanga (Democratic Republic of Congo): a multiscale and a multifactor approach. Biol. Conserv. 12: 767-785.

Paoletti, M.C., Pimentel, D. 1992. Biotic diversity in agroecosystems. Special issue of Agri. Ecosyst. Environ. 40, 3-32.

Peredo P., S.F., Barrera S., C.P., Parada, E. 2002. Efecto de prácticas agrícolas convencionales sobre la biodiversidad de los grupos mesofaunísticos edáficos en un huerto de ciruelos. Una aproximación agroecológica. Agro Sur 30(2), 7-14.

Primavesi, A. 1990. Manejo Ecologico do Solo. Ed. Nobel. Brasil. 549 p.

Schrader S., Kiehne, J., Paulsen, H.M., Rahmann, G. 2006. Development of collembolans after conversion towards organic farming. Aspects of Applied Biology 79, 81-186.

Stork, N.E., Eggleton, P. 1992. Invertebrates as determinants and indicators of soil quality. American Journal of Alternative Agriculture 7(12), 38-47.

Tosso, J. 1985. Suelos volcánicos de Chile. Ministerio de Agricultura, Instituto de Investigaciones Agropecuarias. Santiago, Chile. $723 \mathrm{pp}$.

Zar, F. 1999. Bioestatistical analysis. $4^{\circ} \mathrm{Ed}$. Hall-Ed. Upper Saddle River. New Jersey, USA. $663 \mathrm{pp}$. 